\title{
AN EXPERIMENTAL PROCEDURE TO ESTIMATE LIFETIME OF WATER DROP WITH GRAPHITE INCLUSION UNDER INTENSIVE VAPORIZATION WITH EXPLOSIVE BREAKUP
}

\author{
Jean C. Legros ${ }^{1}$, Vladislav M. Gumerov ${ }^{1}$, and Maxim V. Piskunov ${ }^{1, *}$ \\ ${ }^{1}$ National Research Tomsk Polytechnic University, Tomsk, Russia
}

\begin{abstract}
We developed an experimental setup equipped with tube furnace for continuous heating of heterogeneous drops at a constant temperature and high-speed camera to study characteristics of phase transitions at interfaces of these drops. Also, an experimental procedure was proposed to estimate time characteristics of processes occurring when heated heterogeneous drops in high-temperature environment. As an example, at temperature of heating of $1373 \mathrm{~K}$, lifetime of $15 \mu \mathrm{l}$ water drop with $1 \mathrm{~mm}$ solid inclusion made of natural graphite in high-temperature environment equals almost to $1 \mathrm{~s}$. Experimental data also enabled to reveal minimum temperature at which intensive vaporization of $5 \mu 1,10 \mu 1$ and 15 $\mu 1$ drops with inclusions in size of $2 \times 2 \times 2 \mathrm{~mm}$ proceeds with explosive breakup. This temperature equals to $803 \pm 10 \mathrm{~K}$ depending on initial water volume in heterogeneous drops.
\end{abstract}

\section{INTRODUCTION}

In study [1], the authors discovered the phenomenon of intensive vaporization of heterogeneous (with single graphite inclusion) water drop with the explosive breakup of liquid layer around an inclusion. Moreover, the high temperature of combustion products was defined as a one of the primary condition for implementing the mentioned phenomenon. Using an air flow system enabled to vary temperature conditions in a tube with combustion products. However, the experimental procedure of research [1] includes the difficulty in temperature monitoring. This was quite complicated to measure the temperature at which intensive vaporization of heterogeneous drop with explosive breakup occurs. To solve this problem, the authors determined the temperature ranges conforming to the lifetimes of heterogeneous drops in high-temperature gas environment. Then, average temperatures of ranges were computed. Taking into account the key role of heating

\footnotetext{
*Corresponding author: piskunovmv@tpu.ru
} 
temperature when reaching explosive breakup, determination of this temperature as an average value requires to be clarified.

In this paper, heating the water drop with single graphite inclusion proceeds at constant temperature of gas environment. Definitely, this will allow to determine more precisely temperature which conforms to intensive vaporization of drop with its explosive breakup. Thus, the purpose of this research is to develop and to test an experimental setup providing for continuous heating at constant temperature, as well as to determine temperature conditions for implementing intensive vaporization of heterogeneous drop with explosive breakup of water layer around single graphite inclusion. Moreover, finding the time characteristics of the processes under study is necessary.

Accurate measuring the parameters above mentioned is most critical in developing such technologies as firefighting by using flows with different additives [2], thermal treatment of waste water or industrial water [3], cooling heated surfaces [4-6], etc.

Importantly, the complex mechanism of phase transitions of homogeneous and heterogeneous liquids at temperatures more $1000 \mathrm{~K}$ remains poorly studied. Nevertheless, the operational conditions of the modern power engineering equipment, as well as other applications, in which working cycle is based on the processes of evaporation (condensation) and boiling, are characterized by such high temperatures.

\section{EXPERIMENTAL SETUP AND PROCEDURE}

The main distinctive feature of the given research is an application of experimental setup equipped with tube furnace. fig. 1 presents the schematic illustration of such setup. The used furnace is a one by Nabertherm (maximum temperature of heating is $1573 \mathrm{~K}$; length of ceramic tube is $250 \mathrm{~mm}$ ). Built-in type $\mathrm{S}$ thermocouple enables to monitor temperature of heating with measuring error $\pm 1 \mathrm{~K}$ and response time not more than $5 \mathrm{~s}$. The furnace is also equipped with regulator 9 which allows keeping a constant temperature of heating.

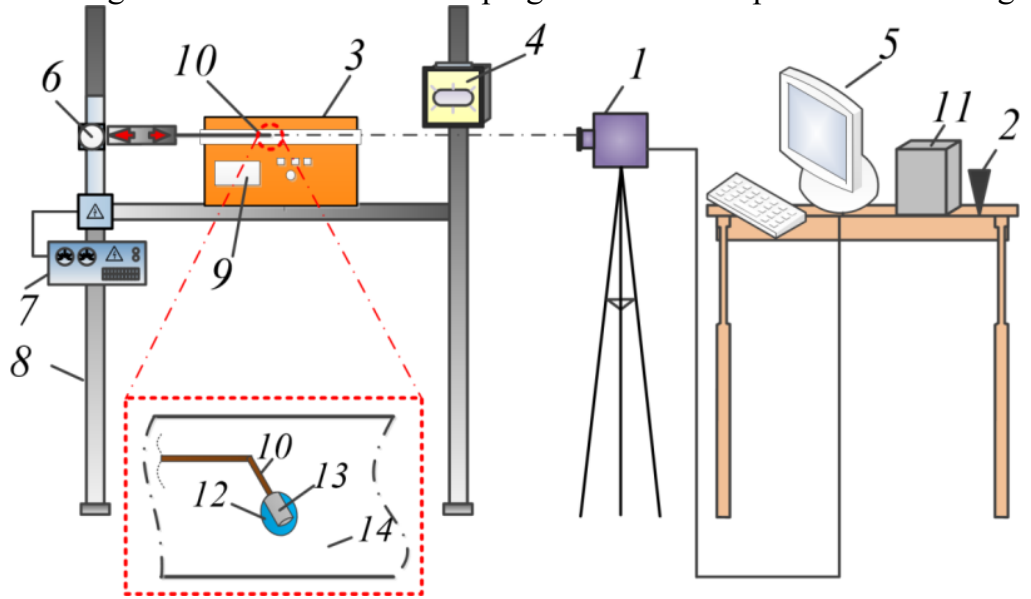

Fig. 1. Schemetic illustration of the experimental setup: 1 - high-speed camera, $2-$ dosing device, $3-$ tube furnace, 4 - spotlight, 5 - personal computer (PC), 6 - moving mechanism, 7 - electric power supply of moving mechanism, 8 - mount, 9 - heating temperature regulator, 10 - ceramic rod, 11 weighing system, 12 - water drop, 13 - solid inclusion, 14 - tube body.

Owing to the design of furnace 3 , we can apply high-speed video camera 1 . It is arranged to the right of furnace 3 in such a way that axis of symmetry of furnace tube is in line with axis of lens (see fig. 1). To the left of furnace 3, moving mechanism 6 transfers water drop 12 with graphite inclusion 13 to tube body 14 . Importantly, motion of 
heterogeneous drop inside furnace continues till center of tube. This distance equals to approx. $125 \mathrm{~mm}$ from the entrance of tube. Such approach provides for reaching temperature, which is displayed on screen of regulator 9 , with required accuracy. During preliminary tests, we measured temperature at the entrance of tube, it was almost two times less than the preset one. Thus, we became to perform experiments at the center of tube.

High-speed video shooting is possible by Nikon macro lens with focal length $200 \mathrm{~mm}$ and color CMOS camera 1 (Phantom V411; maximum resolution is $1280 \times 800 \mathrm{px}$; maximum sample rate is $\left.6 \cdot 10^{5} \mathrm{fps}\right)$. Nevertheless, in the given research, sample rate is comparatively not high (up to $10^{3} \mathrm{fps}$ at resolution $512 \times 512 \mathrm{px}$ or $512 \times 256 \mathrm{px}$ ). However, this speed is quite enough to study features and behavior of heterogeneous drops during evaporation and boiling in detail, as well as to determine time characteristics of the investigated processes. Maximum errors in determining time characteristics are equal to from $0.01 \mathrm{~s}$ to $0.001 \mathrm{~s}$ depending on the preset sample rate in Phantom Camera Control software. In particular, this software provides for time measurement. fig. 2 presents a scheme with times which are determined in the study.

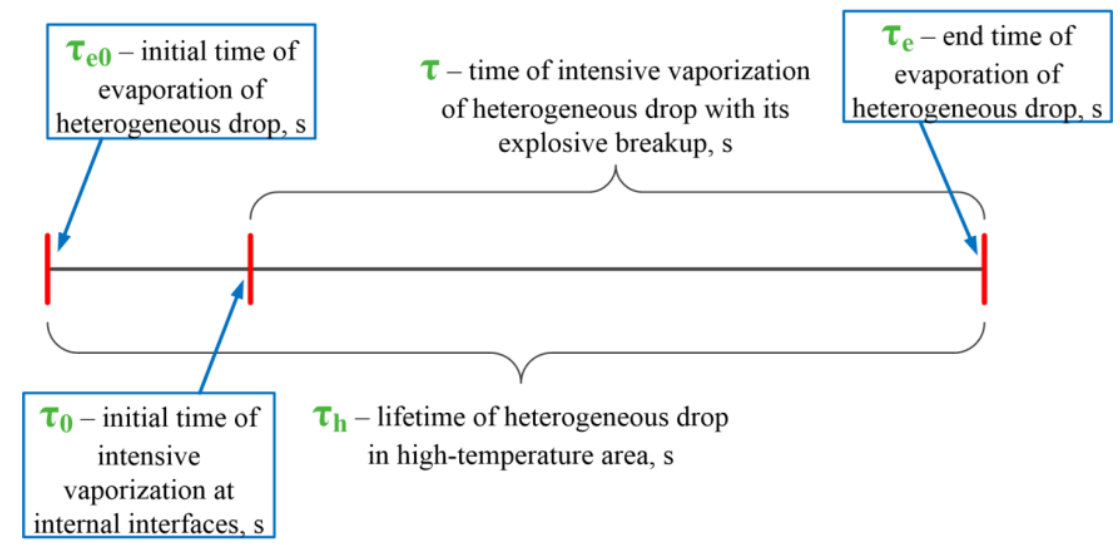

Fig. 2. Schematic illustration of times which are characteristic of the processes observed in the study.

There are several particularities concerning the scheme in fig. 2. The initial time of evaporation of a heterogeneous drop conforms to the time moment when it stops at the center of tube. The end time of evaporation of a heterogeneous drop is determined when analyzing video data during their processing. This time characterizes the moment when water layer of heterogeneous drop is completely evaporated.

Let us briefly consider additional equipment of the experimental setup. Spotlight 4 provides suitable amount of light during high-speed shooting. Dosing device 2 (minimum volume $-5 \mu 1$, maximum volume $-50 \mu 1$, error $\pm 3 \%$ ) enables to take water of required quantity out of the vessel. In all the experiments, the volumes of water drops are $5 \mu 1,10 \mu \mathrm{l}$ or $15 \mu$ l. Importantly, the critically important conditions for performing experiments are full covering of solid inclusion by water droplet and using of new inclusion for each test. In the research, material of solids is a natural graphite [7-9]. We manufacture large inclusions in size: $2 \times 2 \times 1 \mathrm{~mm}, 2 \times 2 \times 2 \mathrm{~mm}$ and $2 \times 2 \times 3 \mathrm{~mm}$; shape: cube and parallelogram. These inclusions are fixed on ceramic rod 10. Then dosing device 2 lowers water drops on them. Also, we weigh solids by analytical balance 11 (Vibra AF 225DRCE; maximum and minimum masses - $220 \mathrm{~g}$ and $0.001 \mathrm{~g}$, respectively; error - not more than $0.5 \%$ ) and monitor their masses during tests.

The experimental procedure of the given study includes the following main steps:

(1) Tube furnace 3 is heated up to preset temperature.

(2) Mechanism 6 moves water drop 12 with inclusion 13 fixed on rod 10 in tube body 14 .

(3) During motion of heterogeneous drop, high-speed recording is activated. 
(4) After completion of water evaporation, ceramic rod 10 with inclusion 13 moves back.

(5) After preparation of the next heterogeneous drop, the steps (2)-(4) repeat.

(6) Analysis of time characteristics and temperature measurement occurs after performing necessary number of series of experiments.

\section{Results and discussion}

For better understanding processes which occur when heated heterogeneous water drop, fig. 3 demonstrates snapshots of heterogeneous drop according with time characteristics which are shown in fig. 2.

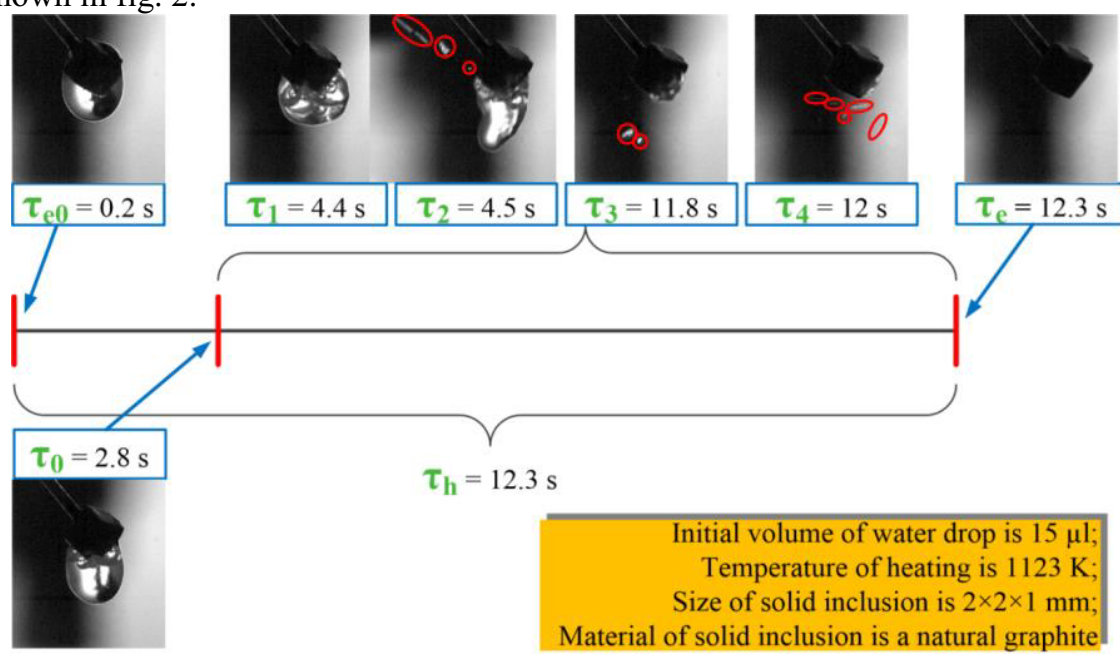

Fig. 3. Snapshots of heterogeneous drop according with time characteristics presented in fig. 2.

In this particular case, lifetime $\tau_{\mathrm{h}}$ is about $12 \mathrm{~s}$. Actually, time characteristics strongly depend on temperature of heating. In the experiments, they vary in the wide range for different configurations of heterogeneous drops (size of solids and water volume). As an example, fig. 4 illustrates lifetimes of $10 \mu \mathrm{l}$ and $15 \mu \mathrm{l}$ drops with solids in size of $2 \times 2 \times 1$ $\mathrm{mm}$ when heated in the range from $1073 \mathrm{~K}$ to $1373 \mathrm{~K}$.

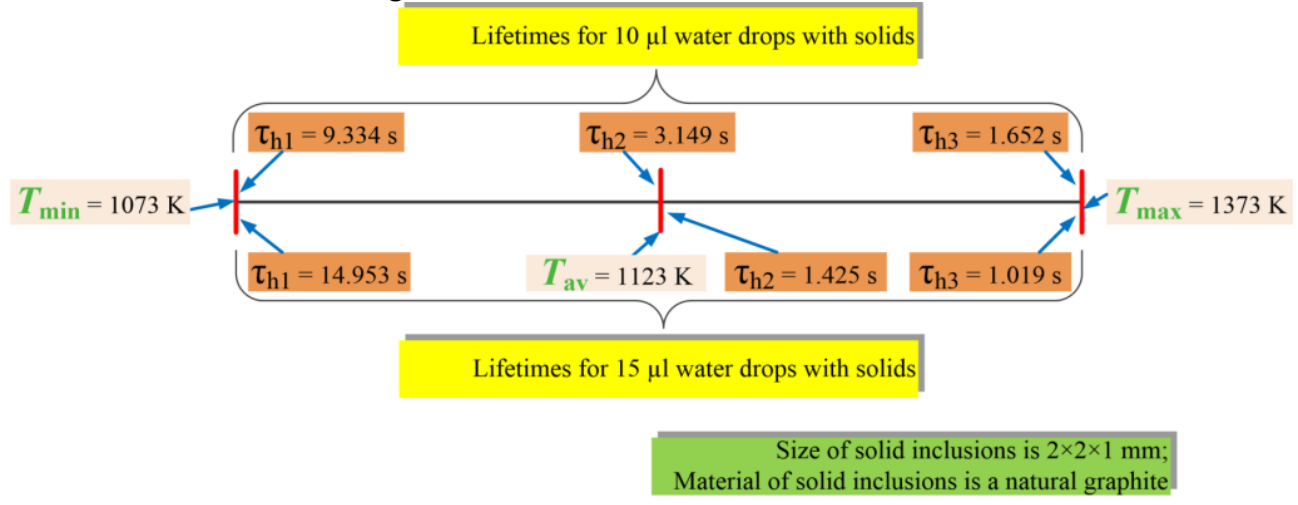

Fig. 4. Lifetimes of $10 \mu 1$ and $15 \mu 1$ water drops with graphite solids in size of $2 \times 2 \times 1 \mathrm{~mm}$ when heated in the range from $1073 \mathrm{~K}$ to $1373 \mathrm{~K}: \tau_{\mathrm{h} 1}, \tau_{\mathrm{h} 2}, \tau_{\mathrm{h} 3}$ are lifetimes of heterogeneous drops at 1073 K, $1123 \mathrm{~K}, 1373 \mathrm{~K}$, respectively.

For water drops with solids of other size, lifetimes at the same temperatures (see fig. 4) differ insignificantly. 
In this research, we determined minimum temperatures of heating at which intensive vaporization of $5 \mu \mathrm{l}, 10 \mu \mathrm{l}$ and $15 \mu \mathrm{l}$ water drops with solids in size of $2 \times 2 \times 2 \mathrm{~mm}$ proceeds with explosive breakup how it is shown in snapshots of fig. 3. Fig. 5 presents schematic illustration of operating temperature range with an indication of the onset temperature of intensive vaporization of heterogeneous drops with their explosive breakup. $T_{\mathrm{ex} 5}, T_{\mathrm{ex} 10}$ and $T_{\text {ex15 }}$ are temperatures of the onset of intensive vaporization for heterogeneous drops with initial water volume of $5 \mu \mathrm{l}, 10 \mu \mathrm{l}$ and $15 \mu \mathrm{l}$, respectively. Note that for mentioned volumes of water, these temperatures are quite close.

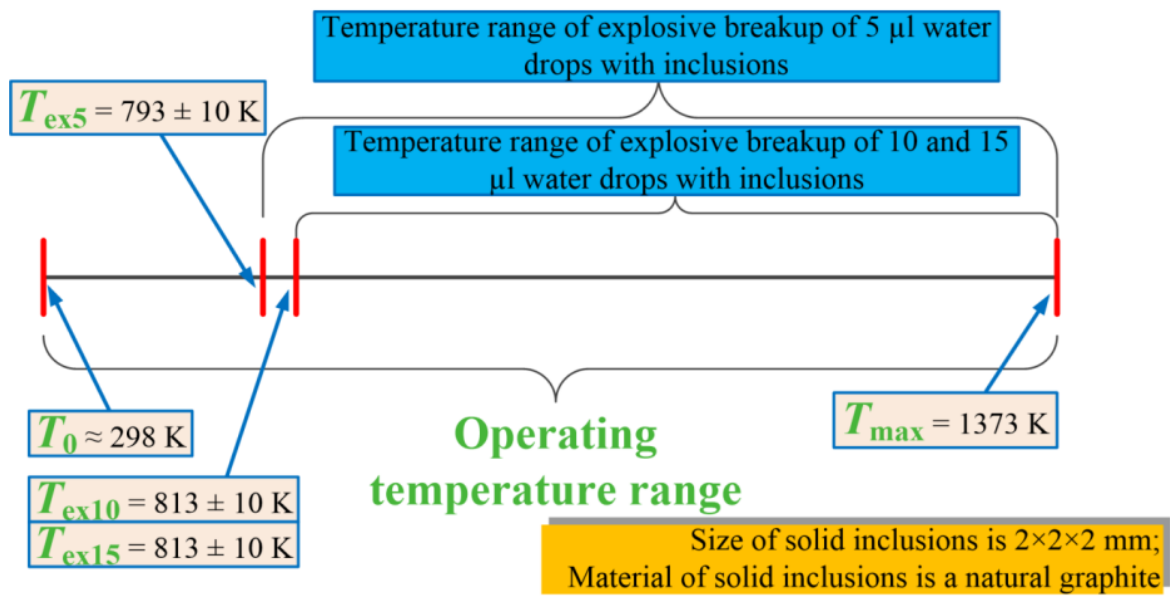

Fig. 5. Onset temperatures of intensive vaporization of heterogeneous drops with their explosive breakup.

The experimental results can be relevant for practical applications where phase transitions occur during operation at high temperatures of environment. In particular, we believe that time characteristics of the observed processes and temperature measurements performed during experiments will contribute to develop energy-efficient solutions in such high-temperature technologies as treatment of industrial and waste water, firefighting by flows of liquids with solid additives, etc. For these technologies, the heat transfer enhancement in the area of interaction between liquids with solids and high-temperature environment is a critically important problem. Thus, investigations on mechanisms, conditions and characteristics of phase transitions of heterogeneous drops at high temperatures are extremely necessary.

\section{Conclusions}

The experimental setup providing for continuous heating of heterogeneous drops at constant temperature was developed and tested. For studying phase transitions at interfaces, these experimental setup was equipped with high-speed camera.

- Intensive vaporization of $5 \mu \mathrm{l}, 10 \mu \mathrm{l}$ and $15 \mu \mathrm{l}$ drops with inclusions in size of $2 \times 2 \times 2$ $\mathrm{mm}$ occurs at temperatures of heating not less than $793 \mathrm{~K}, 813 \mathrm{~K}$ and $813 \mathrm{~K}$, respectively.

- In the paper, lifetimes in high-temperature environment were analyzed for $10 \mu 1$ and 15 $\mu 1$ drops with inclusions in size of $2 \times 2 \times 1 \mathrm{~mm}$. At maximum temperature of $1373 \mathrm{~K}$, lifetime of heterogeneous drop with initial water volume of $15 \mu 1$ equals almost to $1 \mathrm{~s}$. At $1073 \mathrm{~K}$, lifetimes are much more both for heterogeneous drops with water volume of $10 \mu 1$, and for drops with volume of $15 \mu 1$. They equal to about $10 \mathrm{~s}$ and more. 


\section{Acknowledgments}

This work was supported by the Scholarship of the President of the Russian Federation (SP-1049.2016.1).

\section{References}

1. G.V. Kuznetsov, M.V. Piskunov, P.A. Strizhak, Int. J. Heat Mass Transf. 92, 360 (2016)

2. O.P. Korobeinichev, A.G. Shmakov, V.M. Shvartsberg, A.A. Chernov, S.A. Yakimov, K.P. Koutsenogii, V.I. Makarov, Fire Saf. J. 51, 102 (2012)

3. A.Yu. Varaksin, High Temp. 51, 377 (2013)

4. S.-H. Hsu, Int. J. Heat Mass Transfer. 86, 65 (2015)

5. I. Sher, Appl. Therm. Eng. 36, 219 (2012)

6. B.-R. Fu, Int. J. Heat Mass Transf. 95, 206 (2016)

7. D.R. Lide, CRC Handbook of Chemistry and Physics (CRC Press, Boca Raton, FL, 1998)

8. A. Nayer, The Metals Databook (McGraw-Hill, New York, 1997)

9. Metals Handbook, Volume 2 - Properties and Selection: Nonferrous Alloys and Special-Purpose Materials (ASM International, 2001) 